\title{
Short-term retention, presentation rate, and number of display cycles'
}

\author{
M. S. MAYZNER, M. E. TRESSELT, S. ADLER, A. COHEN AND K. M. SCHOENBERG
}

NEW YORK UNIVERSITY

Previous work of Bugelski, Mayzner and Schoenberg, and Murdock has shown that if total display time is held constant, trade offs may be found between number of display cycles (i.e., the number of times a list is repeated before recall is requested) and display presentation rates. The present study extends the se earlier findings by showing that for the shortterm retention of a string of 20 digits, trade offs may be obtained over the range from 1 display cycle and a presentation rate of $8 \mathrm{sec}$. per digit to 16 display cycles and a presentation rate of $1 / 2 \mathrm{sec}$. per digit. A breakdown does apparently occur with 32 display cycles and a presentation rate of $1 / 4 \mathrm{sec}$. per digit, where clear input registration is apparently degraded by the rapidly changing display.

In two previous studies (Mayzner \& Schoenberg, $1965 \mathrm{a}$, b) which examined the effects of presentation rate on short-term retention Ss were presented with lists of digits, one digit exposed at a time on a memory drum. In these studies three variables were investigated, namely, list length $(10,14$, and 18 digits), number of display cycles (single and multi-cycle), and presentation rate $(4,2,1$, and $.5 \mathrm{sec}$. per digit). All three variables produced systematic and highly significant effects $(p<.001)$ on short-term retention and it was concluded that a trade off between number of display cycles and presentation rate is possible, if total display time is held constant, thus supporting the previous findings of Bugelski (1962) and Murdock (1965) using paired-associate material rather than strings of digits.

In the present study, further examination is made of the boundary conditions for which such trade offs, between number of display cycles and display presentation rates, are possible with respect to the shortterm retention of a string of digits. Specifically, if 20 digits are presented for one display cycle at a presentation rate of $8 \mathrm{sec}$. per digit (thus total display time equals $160 \mathrm{sec}$.), is this equivalent to $2,4,8,16$, or 32 display cycles at presentation rates of $4,2,1,1 / 2$, and $1 / 4$ sec. per digit, respectively (with total display time always remaining at $160 \mathrm{sec}$.$) ? The present study seeks$ to answer this question.

Method

The Ss were 20 students from the Department of Industrial Engineering and Operations Research of New York University and had participated in no previous study of short-term memory.

The apparatus used to generate the stimulus strings consisted of a PDP-7 on-line high-speed digital computer coupled to two CRT display consoles (a Master Display, Type 340 and a Slave Display, Type 343; computer and both displays manufactured by the Digital
Equipment Corp., Maynard, Massachusetts). A computer program was written which generated for display strings of 20 random digits, with the constrain. Inat each of the digits zero through nine be used just once in the first and second half of the strings.

Six display cycle conditions were examined. For the one display cycle condition, each of the 20 digits in the string appeared one at a time for $8 \mathrm{sec}$. on the two displays. In the two display cycle condition, each of the 20 digits in the string appeared one at a time for $4 \mathrm{sec}$. Immediately upon completion of the first cycle, the cycle repeated itself once, before recall was requested, and appearing opposite the first digit on the display on the repeat cycle were two asterisks to inform $S$ that the cycle was about to repeat itself. In the four display cycle condition, each of the 20 digits in the string appeared one at a time for 2 sec. Immediately upon completion of the first cycle, the cycle repeated itself three times, before recall was requested, with asterisks used to inform $\mathrm{S}$ each time the cycle repeated itself.

Similar conditions held for the 8,16 , and 32 display conditions, with presentation rates of $1,1 / 2$, and $1 / 4$ sec. per digit, respectively. In order to hold total display time relatively constant for all six display cycle conditions, the time between the change from one digit to the next was fixed at one millisecond, thus in the one display cycle condition, total display time was $160 \mathrm{sec}$. plus 19 msec., while in the 32 display cycle condition, total display time was 160 sec. plus 639 msec., or a little over $160.5 \mathrm{sec}$. It might be noted that the use of ordinary display devices, such as memory drums or slide projectors, would not allow one to keep total display time relatively constant over such a wide range of display cycle conditions, since with the 639 digit changes found in the 32 display cycle condition, appreciable inter-digit display times would accumulate with such slow changing mechanical devices.

Since two CRT display consoles were available, two Ss were run simultaneously, Each $S$ received six different strings, one for each of the six display cycle conditions, always starting with the one display cycle condition and proceeding upward through the 32 display cycle condition. At the completion of each of the display cycle conditions $S$ was required to recall the 20 digits in their correct order, just presented to him, on prepared forms showing a line of 20 dashes, one for each of the 20 digits in the string. Thus, for each $\mathrm{S}$ six dependent response measures associated with each of the six display cycle conditions were available for analysis. 


\section{Results and Discussion}

The mean number of digits correctly recalled for the six display cycle conditions (i.e., $1,2,4,8,16$, and 32 cycles) were $11.4,12.7,12.8,13.7,11.2$, and 4.6 digits, respectively. Application of the Friedman two-way analysis of variance by ranks test (Siegel, 1956, pp. 166172) yields a $\chi_{r}^{2}=37(p<.001)$. However, if the test is applied only to display cycle conditions one through $16, x_{p}^{2}=3.92(p>.30)$. These results suggest then that display cycle conditions one through 16 are probably equivalent, with a marked decrement in recall occurring only for the 32 display cycle condition, which had a presentation rate of $1 / 4$ sec. per digit, and where almost all Ss stated the display changed so rapidly a "clear" perception of the stimulus string itself was very difficult, if not impossible.

It would appear from the findings of the present study that a trade off between number of display cycles and display presentation rate, with total display time held constant, is possible over a fairly wide range of display cycle and presentation rate combinations. This trade off occurs from one cycle and $8 \mathrm{sec}$. per digit to 16 cycles and $1 / 2 \mathrm{sec}$. per digit, with a breakdown oc- curring apparently only when a "clear" perception or registration of the stimulus string itself is produced resulting from very rapid display changes (i.e., $1 / 4 \mathrm{sec}$. per digit). The present results clearly support earlier findings of Bugelski (1962), Mayzner \& Schoenberg (1965b), and Murdock (1965) and add further generality to the phenomena over a much wider range of display cycle and display presentation rate combinations.

\section{References}

Bugelski, B. R. Presentation time, total time, and mediation in paired-associate learning. J. exp. Psychol., 1962, 63, 409-412.

Mayzner, M. S., \& Schoenberg, K. M. Short-term retention and presentation rate. Psychon. Sci., 1965a, 2, 111-112.

Mayzner, M. S., \& Schoenberg, K. M. A further study of short-term retention and presentation rate. Psychon. Sci., 1965b, 3, 159-160.

Murdock, B. B., Jr. A test of the "limited capacity" hypothesis. J. exp. Psychol., 1965, 69, 237-240.

Siegel, S. Nonparametric statistics for the behavioral sciences. New York: MeGraw-Hill, 1956.

\section{Noie}

1. This research was supported in part by Contract Nonr $285(56)$ between the Engineering Psychology Branch of the Office of Naval Research and New York University. 